\title{
IMPLEMENTATION METHODOLOGY OF COMPLEX MANUFACTURING ENVIRONMENT IN A BROWNFIELD SITE
}

\author{
António Brandão Moniz ; Paula Urze ${ }^{2}$ \\ ${ }^{1}$ Faculdade de Ciências e Tecnologia, UNL, abm@fct.unl.pt \\ ${ }^{2}$ UNINOVA-CRI, pcu@uninova.pt
}

\begin{abstract}
This paper discusses a methodology for the implementation process of a flexible machining and assembly manufacturing system in an existing site (an existing industrial infrastructure), or brownfield site. The reference laboratory test site, a Flexible Manufacturing System FMS installed at the UNINOVA Institute, was used to validate the designed methodology. Studies based on real industrial environments were also considered, in order to incorporate added key influencing variables to the proposed methodology. The methodology points to the implementation of a technological system under a generalized participative approach. The involvement of managers, technicians and workers in the design and implementation making them feel that the changes are not marginal events in relation to their activities, is a key guideline discussed in the paper.
\end{abstract}

\section{INTRODUCTION}

The technological innovation of an existing production infrastructure, a brownfield site, requires an implementation plan that considers both technology design and social and organizational issues. This balanced approach to the new manufacturing systems implementation aims to guarantee that the expected goals can be successfully achieved. The proposed methodology is grounded on an extended discussion among technologists and sociologists on how to implement an information and communication technology involving process reengineering and organizational changes in virtual enterprises. The results of the PRODNET project involve a methodology that was design to guide the innovation process of an enterprise considering its participation in a virtual enterprise using the PRODNET developed infrastructure.

This proposed methodology is based on a set of features of the pilot unit (NovaFlex) installed at UNINOVA-CRI's laboratory (Intelligent Robotics Center). This laboratory unit is composed by a Flexible Manufacturing System (FMS) organized around three cells: a machining cell (with a robot and two CNC machine tools), a logistics cell (with a transport conveyor with PLC's, and a flexible warehouse with a programmable manipulator), and a flexible assembly cell (with 
two different types of assembly robots). These three cells have different levels of automation and associated computer assisted tools.

There is an added complexity when a brownfield site is considered based on the fact that several legated knowledge, systems and culture are usually inherited. The NovaFlex pilot unit is being studied to analyze the social and the technical characteristics to be extrapolated to SMEs with similar production infrastructures and involved in technological innovation processes. This study aims to consolidate a methodology for the establishment of a mapping between the "as is" and "would be" situations, considering a smooth transition where it is desired that all the involved actors adopt the ownership of the changes. Important targets are the small and medium enterprises where the laboratory case can be replicated to batch production of metal-engineered pieces with critical functions of accurate assembly. There are no specific working conditions problems unless those related with repeated tasks with short term decreasing accuracy that can contribute to the final product with quality problems. The application sectors may be broader, however there is a likelihood to be applied in the production of small and complex metal products (for example, to the automobile industry), in the electronic devices (from home appliances to medical and healthcare products), or even in the micro-electronic sector.

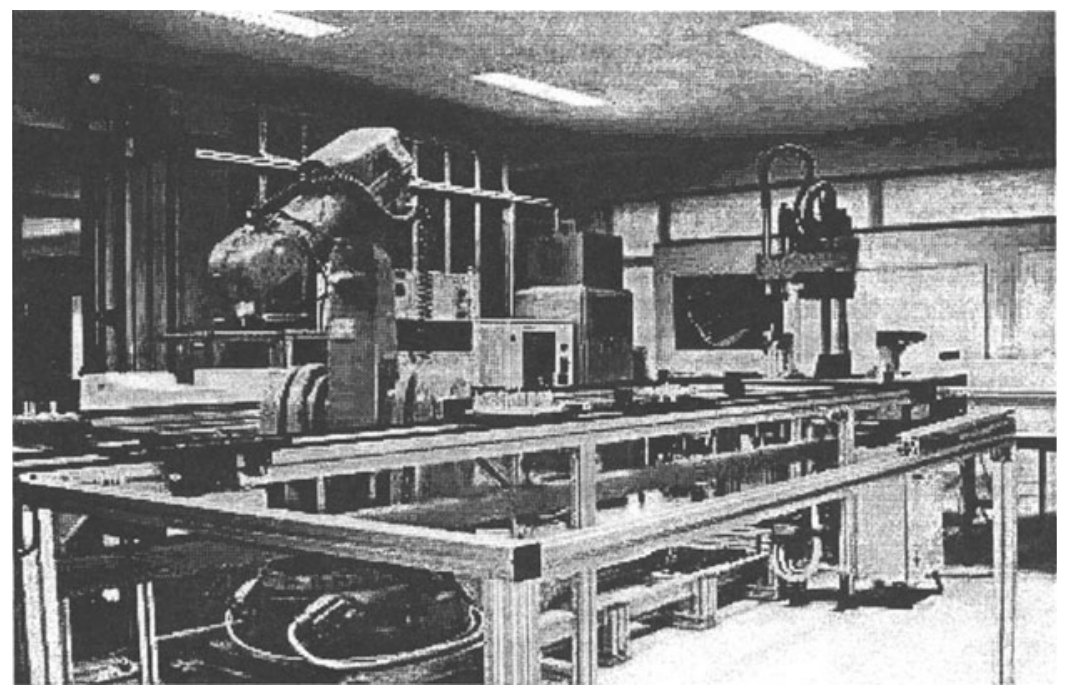

Figure 1 - View of the CRI's pilot flexible machining and assembly manufacturing system

It is important the workers involvement in the adoption of the evaluated systems associated with the required changing processes in order to makes them feel the changes not as marginal events in relation to their activities but, as changes which success depends on their participation (Kovács, 1998). The involved persons might feel themselves as co-authors of the changes, behaving with an interested participation in the technological and organizational realignment. The progressive 
participation (earnestly) of those affected by the changes becomes on what Einar Thorsrud called 'project owning' (Teixeira, 1996).

Some authors and pioneer experiences in the social sciences area (sociology, management and psychology) points to the implementation of a technological system under a participative approach. The HITOP methodology reported as the High Integration of Technology, Organization and People (Majchrzak et al, 1991) is an example of such a balanced approach considering technology, organization and people as the key elements grounding the underlying changes. Example of other experiences is the Industrial Democracy Project developed in Norway and Sweden during the 60's and 70's, aiming to spread new forms of work organization in the national industries to promote the participation of the workers (Ortsman, 1978; Gyllenhammar, 1977). Other cases were developed in Holland (the Phillips case was described by den Hertog, 1977), England (Herbst, 1974), and others (Davis and Wacker, 1987, Brown, 1997, Noon and Blyton, 1997, Danford, 1998)

\section{DESIGN OF THE IMPLEMENTATION METHODOLOGY}

Based on the implications of the implementation of the new pilot unit, the workers need to acquire a precise understanding of the new working resources (robotics, CNC machining, conveyors, flexible warehouses, PLC, CAP and others) and working process. The new environment is expected to present the following new characteristics:

* Workers have to operate new machinery requiring added skills in complex (mental and physical) environments. They are expected to operate new production tools under different production processes. These can be CNC machine tools, robots or computer controlling systems.

- The interaction with enterprise applications reflects the new automated manufacturing system carrying out a new set of devices, words and concepts to be used in different data bases. They have to be understood by workers in order for them to operate correctly the new interfaces.

* The workers are required to acquire a holistic perspective of the production system, moving their skills from an excessive specialization to an extended set of competencies with a wider vision of the enterprise activities. This is more important when semi-autonomous working groups incorporate the manufacturing cells.

From a general perspective, all workers are affected by the new manufacturing technologies. The production can take advantage of several technological features to reorganize the work system.

Figure 2 shows the different phases an innovation process might follow from the technological (sociological) design point of view. A macro observation of the technological implementation process points out the adoption of new enterprise technologies, under the following phases:

* research and development project - solutions are created in order to improve production efficiency under social and organizational constraints; 
- prototypes of the new technological innovation - the solutions can be validated against end-user requirements through simulation of prototypes and products;

* pilot experience - implementation of the new technology is realized considering a restricted area of the enterprise (cell, department) aiming to validate a real operation;

- extended pilot experience - from the pilot experience and based on the research, development and demonstration, a set of guidelines are elaborated in order to establish accurate implementation methodology;

- learning from experiences - real case studies are evaluated in order to adjust the implementation methodology and, if necessary, the technological aspects.

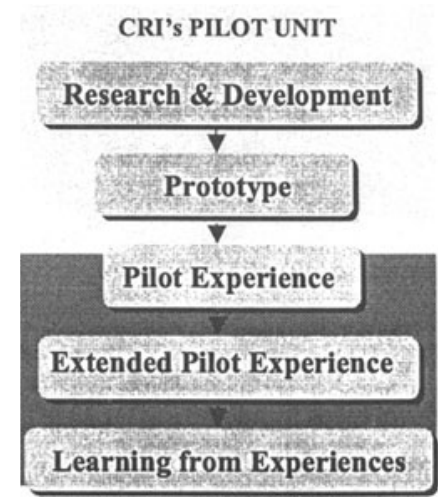

Figure 2 - Technological innovation phases

The TOD-CME project is positioned at the beginning, see Figure 2, covering the research and development phase complemented with a laboratory demonstration. In order to consider the implementation aspects beyond these two phases, other case studies (Kovács, 1996, Urze, 1996, Danford, 1998, Moniz, 1999) were considered during the establishment of the proposed methodology.

\subsection{Enterprise management commitment}

An initial step toward a fruitful adoption of the technology involves the commitment from the enterprise management. This can be done creating a business view of the demonstrator stressing the competitive advantages into the market. The following points might be considered:

* competitive advantages on the competitive market requiring efficient (fast) product innovation;

- required investment including cost to re-engineer the actual enterprise processes and the capacity to integrate the enterprise legated systems; 
* an active participation of all intervening workers is required by the new technological system. The reorganization should clarify the worker's role in the new work system design.

There is a natural resistance to the changes considering that they involve several risks, not only technological but also related with difficulties to integrate all the human resources. For companies that do not have any flexible production system, and companies without any innovation culture, it is necessary to present the added required machining and computational infrastructure. Often, the technology changes induce in an easier way the organizational restructuring at the shop-floor level. Furthermore, it is mandatory to present an investment plan specifying all the machines, robots, conveyors, computers, communication network and other equipment necessary to obtain an operative and integrated cell. The analysis of costs of such operations might include the target objectives in different scenarios. But at least one of those should be related to the possibility of organizational change with evident impact in terms of productivity. The scenarios are the best tools for a negotiable agreement among the involved actors.

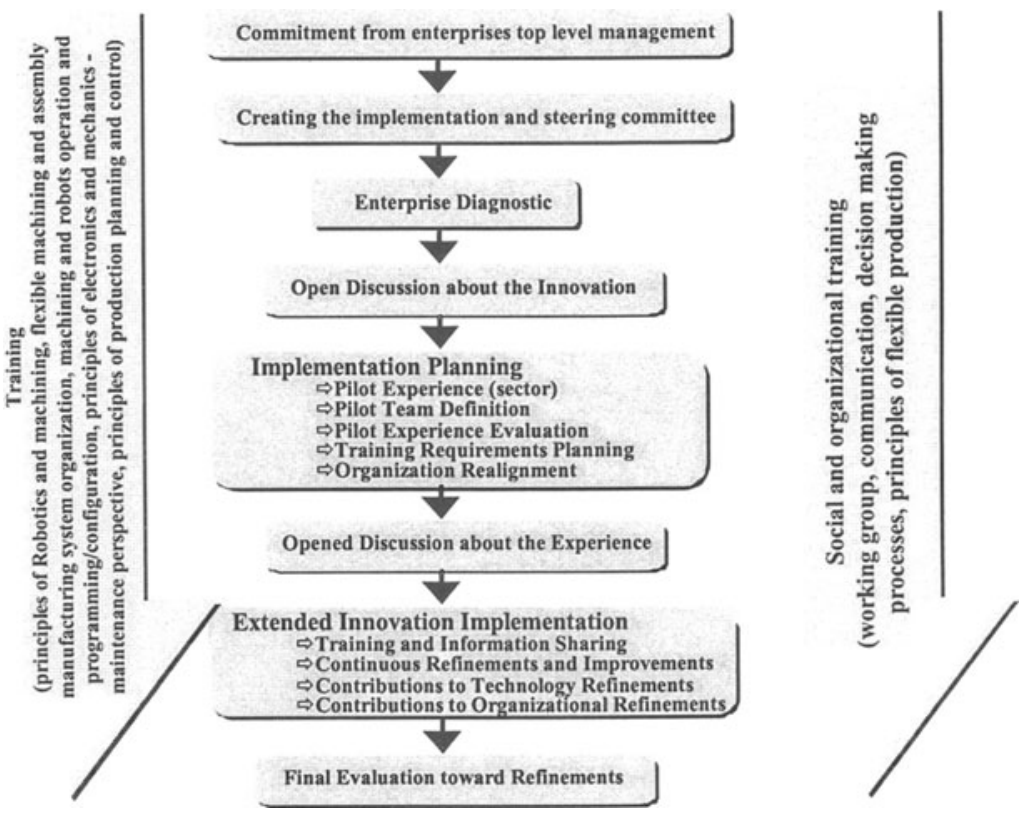

Figure 3 - Implementation phases 


\subsection{Steering committee}

The establishment of an implementation and steering committee, integrating representatives from the workers, from management and also from the administration, aims to consolidate the administration commitment and also to join the enterprise competencies to lead the implementation process. This team usually involves an external consulting team, bringing to the SME the needed added knowledge to support the implementation. The team might involve competencies on industrial automation considering both, sociological and technological domain knowledge. The inclusion of a key person in the committee with a deep knowledge about all the enterprise sectors, their structure and processes is also important.

One important aspect is to guarantee that the added experience brought by the external consultants is converted positively to the dynamic of the implementation committee, contributing to its autonomy reducing, along the time the influence/need for external advise. The consultant team/company is supposed to bring other implementation experiences and an extended view of the technology and a refined implementation methodology. This synergy can join the implementation committee in order to merge the enterprise culture (enterprise memory - other implementation experiences, process reorganization, etc.) with the standard implementation approaches.

The presence of consultants during the implementation can be seen as a catalytic factor to the changing process, playing in some sense, a mediator role for all natural opposing forces that often emerge during the changing project. Workers, who want to maintain their status quo, might oppose substantial changes to the organizational structure. Often, workers and managers only recognize the personal disadvantages such as the fear of loosing their jobs, responsibility, and power, among other things. These obstacles might be overcome by giving information and through an intensive participation of the affected employees when the new scenario is designed. A successful implementation can only be achieved if there are no doubts about the direction and the objective of the change.

\subsection{Enterprise Diagnosis}

The Enterprise Diagnosis aims to establish the enterprise characteristics from the human resources, infrastructure, cultural and organizational viewpoints, considering the "as is" enterprise situation. Taking into account the complexity of any enterprise investment, it is important to evaluate not only the "as is" but also to make a projection of the consequences on adopting the new technology considering organization, skills (work contents) and market environment (competition). The diagnostic should be focused on the evaluation of aspects that directly or indirectly may affect the innovation process.

From many other aspects, the evaluation of the social, organizational and technological issues should be primarily considered. The two first mentioned aspects involve the organizational culture, the organizational structure, the work organization and the human resources characteristics. The last one (technology) includes the analysis of the existing machines, robots and other technological equipment that have to be integrated/substituted in the new scenario, and also the implications from the integration of new equipment in the enterprise shop floor. The 
adoption of new equipment involving complex manufacturing systems (FMS, networking, computers) needs to be integrated with other production areas and/or with other enterprise departments.

\subsection{Open discussion}

Established the investment/innovation fundaments, an open discussion based on the results of the diagnostic, is important as a starting point to generate suggestions for the preliminary implementation (the pilot action plan definition). This discussion should be organized as brainstorming sessions with the implementation committee. The collected suggestions might contribute to consolidate the decision of investment and to support an extended debate within the enterprise. This phase is expected to produce a set of supported recommendations to be presented to administration.

\section{THE PILOT IMPLEMENTATION PLAN}

In order to create a smooth path between the "as is" situation and the operation with the new flexible production cell, the implementation methodology points to the establishment of a pilot experience with a step by step adoption of the new production system.

The cell installation involves several configuration steps most of them performed by the cell supplier. There are specific configuration steps for each company, according to the specificity of their production infrastructure. In any case, these aspects will be detailed in the installation and operation manuals of each cell component.

Considering that the cell systems are operational, the next step is to install the new reengineered production processes in order to start to operate with the new production resources. In addition to the cell operation there are other management tools to help the workers to deal with the new flexible cell subsystems. As an example, if it is necessary to initiate the production of a new product there are programming steps necessary to be performed to reconfigure the cell to produce the new product. Therefore, for the pilot experience it is advisable to select a restricted group of workers. At the beginning a minimal group is enough to start to operate with the new flexible cell.

During at least six months, the involved workers dealing with the new cell might have the opportunity to test the new facilities offered by the cell pilot installation. During this period, the involved workers are supposed to receive training (room and job training) in order for them to understand the characteristics and processes of the new systems. A social training (efficient communication, co-operation, group problem solving, teamwork, etc.) must be organized around a modular structure. This organization creates a flexible continuous knowledge acquisition, directing specific topics according to the training expectation and needs. The technical training (cell operation, assembly and production concepts, etc.) might also follow a modular structure enabling a more flexible access from the involved workers.

The production manager plays a key role during the pilot experience and also during the final implementation to all the enterprise. The production manager is the 
key person to acquire a deep knowledge about the new cell and to play later the role of trainer of the new involved workers during the pilot experience and the final implementation (a key person on knowledge transfer among enterprise production sectors).

The generated implementation plan, later refined with the results of the pilot experience, should guide all the innovation process. The implementation committee will have a fundamental role in all the innovation as it is supposed to balance the enterprise person sensibilities playing the role of culture unification, creating during the process a team feeling.

A pre-condition to the success of the experience requires the acceptation and commitment of the selected workers for the pilot team. It is the responsibility of the implementation committee to facilitate the co-operation with other sectors not directly involved in the pilot experience. The creation of a generalized support to the changes is a pre-condition to minimize the resistance.

Whilst the pilot experience implementation team has a great flexibility of actions and decision making, a significant number of evaluation milestones should be planned in order to avoid the process instability and to promote a learning process from the evaluation of the partial results. During the pilot phase it is important to consider production breaks as consequence of the technological innovation. This preventive position from the administration may avoid misinterpretation of production results under the expected levels.

There is a group of other aspects that may be considered for the pilot experience:

* the selected pilot sector should be able to demonstrate a maximal number of the new required functions (flexible product change, production quality, and work places with enhanced responsibility, etc.);

* definition of the functionalities to be implemented during the pilot experience: product production change, machining programming / configuration;

- evaluation of the cell resources and communication infrastructure installed at the pilot sector in order to support the pilot experience (robots, machines, conveyor, control system);

* characterization of the role each person will play during the pilot experience.

The pilot experience should terminate with an extended conclusion (final evaluation report) pointing to a decision to pass or not to the extended implementation phase or to refine the innovation process considering the experiences resulting from the pilot implementation. The following points should be considered during the evaluation of the pilot results:

* evaluation of the infrastructure operation level;

* if all the cell components fulfil the expressed requirements;

- if all the workers are adhering to the innovation process with a good performance;

* if the performance of the involved processes is according to the expected levels;

The results obtained from the pilot experience and from the effective innovation implementation may contribute to improve the technology. The feedback to 
researchers and implementation consultants (interdisciplinary team with sociologists and technologists from different application domains) may contribute to improve their views of the technology and organization realignments.

\subsection{New Concepts: Implementation and Training Requirements}

A major aspect related to the technological innovation is the information and training of the enterprise workers and management staff. It must consider the personal development based on the individual as a whole. Considering that the flexible manufacturing and assembly system technology involves different enterprise sectors, it is advisable to get a generalized adherence, to provide that all the enterprise workers have an enough understanding of the technology being adopted.

This approach has the main advantage to promote a smooth organizational culture realignment considering the adoption of new concepts and procedures.

The presentation of the new concepts and procedures can be done through information sessions where workers are informed about the evolving strategy. In order to obtain a significant adherence, it is important to initiate the information/training since the beginning of the innovation process. The "sociotechnical" information/training plan should be organized according to the target individuals considering their role in the innovation process, Figure 4.

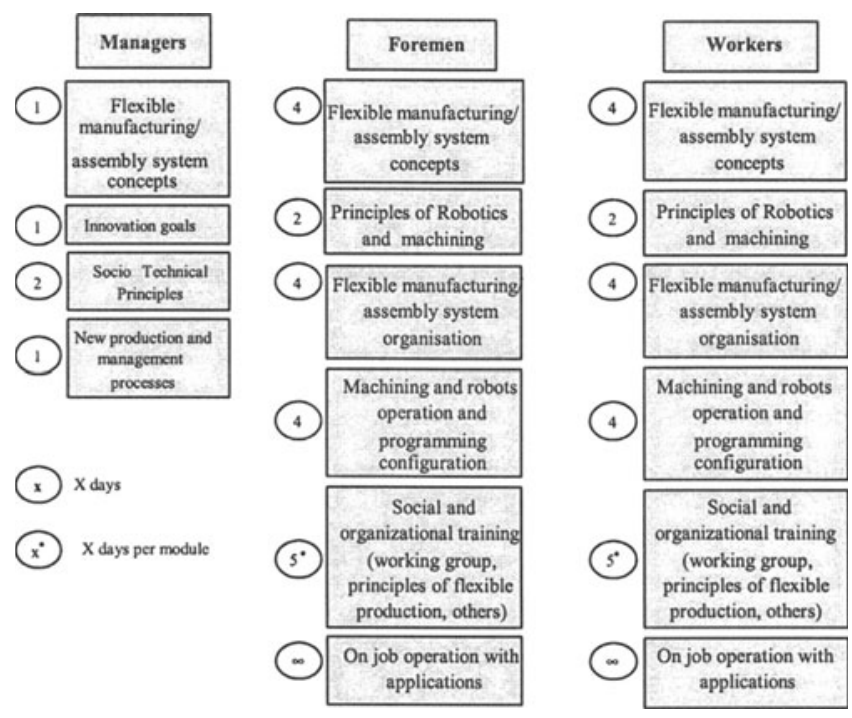

Figure 4 - Training contents

* Training of production management staff - All the strategic enterprise persons should be informed about the proposed innovation (characteristics, costs and advantages) and about the technology to be implemented: flexible production concept, manufacturing and assembly 
system functionalities, reengineered processes, decision making flow changes;

* Training of foremen/workers (configurations) - Detailed training plans are necessary to put the enterprise workers able to operate with the new technology and in the new organizational scenario. This can involve the move of some workers to new activities requiring new skills: robot operation and configuration machining operation and configuration;

* Training of workers not directly involved - Considering that the innovation process can create instability and it has some level of risk, the workers should be informed about the technology being implanted and also about the advantages it can bring to the enterprise: flexible manufacturing and assembly systems.

From this perspective, training activities should be applied not only to the people involved in the organizational restructuring, but it can be also a motive to enhance the training and qualification infrastructure at the company level. This is more critical when the manufacturing environment is more complex concerning task contents.

Finally, another important aspect is centered on the growing utilization of on-line documentation through the web infrastructure (Intranet) or another specialized browse facility. The training on manual utilization can create a space for a continuous knowledge transfer, contributing to the movement toward a learning organization.

\section{CONCLUSIONS}

This paper discussed a methodology for the implementation process of a flexible machining and assembly manufacturing system in an existing site (an existing industrial infrastructure), or brownfield site. This methodology can be implemented in a real industrial environment where several variables can be considered as strongly influent for the success of this process.

In fact, one of the main conclusions from the literature case studies, underlines the possibility that, when there is a need to implement a technological system, the success depends on the development of a participative approach. The involvement of managers, technicians and workers in the design and implementation makes them feel that innovations in the context of the restructuring process is not a marginal event in relation to their daily activities. The changes depend on the success of their participation. The involved workers and technicians can be considered as co-authors of the project. In this way they can participate in the technological and organizational requirements, improving the results searched.

We can conclude that all workers are affected by the new manufacturing technologies. The production activities can take advantage of several technological features to reorganize the work system. This can occur if the technological implementation process points out the adoption of new enterprise technologies, following the incremental steps as: the research and development project, the prototypes of the new technological innovation, the pilot experience (in one flexible 
manufacturing cell, for example), the extended pilot experience to other cells, and the learning from experiences (with an evaluation process).

The success requires an involvement and the commitment from the enterprise management. At the same time, we can consider that the scenarios can be the best tools for a negotiable agreement among the involved actors. Nevertheless, the establishment of an implementation and steering committee integrating representatives from the workers, from management and also from the administration, aims to consolidate the administration commitment and also to join the enterprise competencies to lead the implementation process.

We can conclude also that the results obtained from the pilot experience and from the effective innovation implementation may contribute to improve the technology itself. The feedback to researchers and implementation consultants may contribute to improve their views of the technology and organization realignments.

\section{Acknowledgement}

This work has been partially supported by the PRODNET an Esprit project promoted by the European Commission and by the TOD-CME project financed by the Portuguese Foundation for the Science and Technology (JNICT-FCT).

\section{REFERENCES}

1. Brodner, Peter - High Performance Manufacturing - The New Comprehensive Change, in Paul, $\mathrm{H}$ and Pekruhl, U (Eds.) Aspects of Integrated Company Renewal, Gelsenkirchen-IAT, 1997.

2. Brown, Richard K. (ed) - The Changing Shape of Work, Houndmills, Macmillan, 1997.

3. Danford, Andy - "Work organisation inside Japanese firms in South Wales: A break from Taylorism?" in Thompson, P. and Warhurst, C. - Workplaces of the Future, Houndmills, Macmillan, 1998.

4. Davis, L.E.; Wacker, G.J. - "Job Design" in Salvendy, G. (ed.) Handbook of Human Factors, New York, Wiley, 1987.

5. Eijnatten, F.M. - The Paradigm that Change the Work Place, Arbetslivscentrum, Stockholm, 1993.

6. Gyllenhammar, P.G. - People at Work, Reading, Addison-Wesley, 1977.

7. Herbst, P.G. - Socio-Technical Design, London, Tavistock, 1974.

8. den Hertog, J.F. - "The search for new leads in job design", Journal of Contemporary Business, (6) 2, 1977

9. Kovács, Ilona - New models of production: work and people (collaboration with Juan Castillo), Oeiras, Celta Ed., 1998.

10. Kovács, Ilona. - New Production models: some results from research project, Organizações $e$ Trabalho, 18/19, Lisbon, 1997.

11. Majchrzak, A., Fleischer, M., Roitman, D., Mokray, J. - High Integration of Technology, Organization and People - HITOP, Ann Arbor, ITI, 1991

12. Moniz, A. B. - "Organizational alternatives for flexible manufacturing systems", Proceedings do World Meeting of Labor Studies and Sociology of Work, Mayaguez, Puerto Rico, Univ. Puerto Rico/ISA RC30, 1996, 10 pp.

13. Moniz, A. B., Soares, A. Lucas - Issues in Techno-Organisational Development Methods for Complex Manufacturing Environments in Matos, L.C., Raprasadeh, M. (eds.): Balanced Automation Systems- BASYS' 95, Chapman \& Hall, 1996.

14. Moniz, A. B., Teixeira, C., Urze, P., Bento, S. - About the Apprenticeship Work Content, in APSIOT, Formação, Trabalho e Tecnologia, Oeiras, Celta, 1998.

15. Moniz, A. B., Urze, P. - Socio-Organizational Requirements for a VE, in Matos, L.C. and Afsarmanesh (Eds) Infrastructures for Virtual Enterprise, 1999.

16. Morgan, Gareth - Images of Organisation, Sage Publications, 1996.

17. Noon, M., Blyton, P. - The Realities of Work, Houndmills, Macmillan, 1997. 
18. Ortsman, Oscar - Changer le Travail, les Experiences, les Methodes, les Conditions de L'Experimentation Sociale, Paris, Dunod Enterprise, 1978.

19. Teixeira, Cláudio - Work organization and human factor, Lisbon, IEFP, 1996.

20. Urze, P., Moniz, A.B., Osório, A. Luís - Toward the Virtual Enterprise Paradigm: a Cultural and Technological Information Network in Proceedings of the XIV World Congress of Sociology, Montreal, ISA, 1998. 